Research Article

\title{
WomBot: an exploratory robot for monitoring wombat burrows
}

\author{
Robert Ross $^{1}$ (1) Scott Carver ${ }^{2} \cdot$ Elizabeth Browne ${ }^{2} \cdot$ Ba Son Thai $^{1}$
}

Received: 8 February 2021 / Accepted: 20 April 2021

Published online: 08 June 2021

(c) The Author(s) 2021

OPEN

\begin{abstract}
In this study we evaluate the design and efficacy of Wombot, an exploratory robot used to study environmental conditions within wombat burrows. Our purpose-built robot traverses through the difficult terrain present in wombat burrows whilst facilitating placement and retrieval of environmental data loggers. Our preliminary results suggest that the environmental conditions present within the burrows would result in a long mite survival time which shows significant risk for spreading infestations throughout a wombat population.
\end{abstract}

\section{Article Highlights}

- Wombats live in difficult to observe burrows and suffer from mange cased by Sarcoptes scabiei.
- A teleoperated robot was designed to traverse the difficult terrain within burrows whilst placing and retrieving environmental loggers.

- Cool and humid environmental conditions within burrows suggest a relatively long mite survival time of 16-18 days

Keywords Field robotics - Wildlife conservation - Tele-operation

\section{Introduction}

The act of living partially or entirely underground (e.g. caves, burrows, dens) or using hidden environments (e.g. tree hollows, with leaf litter, dense vegetation) makes research into the ecology and health of many animal species a challenge. The essential issue arises from difficulty in obvserving species within these hidden environmentsmeaning that aspects of their ecology are not easily understood. For example, aspects of the social ecology of some mole species, and aspects of the reproductive biology of winter hibernating bears have remained long-standing research challenges. Additionally, some of the most significant wildlife pathogens can be transmitted in hidden environments. For example, the fungal agents that cause bat White Nose Syndrome and amphibian chytridiomycosis can be transmitted in caves and moist substrates under rocks and leaf litter, respectively. Thus, understanding the 'hidden' ecology of species and environments is both a difficult and important issue. To overcome such issues technological solutions are often the best answer (e.g. hidden or remote cameras, attachment of retrievable accelerometers to individuals, and vehicles).

Wombats are medium sized, herbivorous marsupials which are fossorial. They create burrows for shelter and thermoregulation from diurnal temperature extremes [32]. Three species of wombats occur in Australia, the barenosed wombat (Vombatus ursinus, a.k.a. common wombat)

Robert Ross, R.Ross@latrobe.edu.au| 1 Department of Engineering, La Trobe University, Bundoora, Victoria 3086, Australia. ${ }^{2}$ Department of Biological Sciences, University of Tasmania, Hobart, Australia.

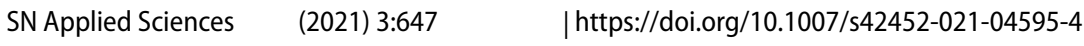


across southeastern temperate regions (far southeast Queensland, eastern New South Wales [NSW], Victoria, Tasmania, and southeastern South Australia), the southern hairy-nosed wombat (Lasiorhinus latifrons) in arid south areas (South Australia and into Western Australia) and the critically endangered northern hairy-nosed wombat (Lasiorhinus krefftii) is restricted to two arid areas of inland Queensland [32]. All three species are primarily nocturnal and prefer cooler temperatures, although they will also forage in diurnal periods during cooler conditions. Burrows are dug into substrate that varies in composition of clay, sand, and obstructions (e.g., rocks, tree roots). Bare-nosed wombats typically dig single burrows, often occupied by a single individual, whereas the hairy-nosed species tend to create warrens each of which can be occupied by several individuals [32]. Evidence indicates the environmental conditions (temperature and humidity) within wombat burrows are relatively stable over circadian cycles [28]. However, the stability of environmental conditions across seasons is less well understood. Indeed, for bare-nosed wombats (the focal species of this study), it is well known that they can vary their use of burrows owing to seasonal changes in environmental conditions (e.g. flooding from changing water tables).

The subterranean environment which wombats utilize, has been a long-standing challenge to study. The earliest investigations of wombat borrows came from the sketches of the Australian Peter Nicholson during his childhood in the 1960's. He crawled into the burrows of bare-nosed wombats in NSW, partially excavating aspects to facilitate maneuvering [32]. Of course, certain safety and ethical risks are presented by this-entrapment in confined spaces, cave-ins, aggressive wombat encounters, and the necessity of small-statured individuals (children) for exploration-hence other research methods are necessary. Other studies to document the structure and environmental conditions of wombat burrows have included excavation (destruction), drilling of a sequential series of portholes directed by mirrors and cameras and, more recently, ground-penetrating radar (GPR) $[19,31,32]$. These studies document heterogeneity in the length of burrows (generally $<10$ meters, longest 89 meters), number of entrances (generally $1-2$, up to 28), amount of branching, and terrain (including substrate [compact soil, dry friable sand, submerged sections, muddy conditions], vertical inclines [up to $45^{\circ}$ ] with angles [up to $180^{\circ}$ within $50 \mathrm{~cm}$ ]) $[19,28$, $31,32]$. A single study has investigated the behaviour of wombats within burrows using accelerometers glued into the hair of the wombat dorsum [17]. During early experiments we trialed the use of wireless remote vehicles to traverse burrows but found that this was infeasible due to rapid signal attenuation as the burrow was traversed.
Understanding the environmental conditions within the burrows of wombats has important implications for their health. The most important disease of wombats (particularly bare-nosed wombats) is sarcoptic mange, which is caused by the parasitic mite (Sarcoptes scabiei Linnaeus, 1758) [15]. This parasite has been documented to infect greater than 100 species of mammals around the world [4, 23]. It is also a significant human parasitic disease (scabies), considered a Neglected Tropical Disease by the World Health Organisation [20]. Evidence indicates that S. scabiei is transmitted environmentally among bare-nosed wombats $[16,29]$. Wombat individuals are largely solitary, rarely coming into direct contact, but will switch the burrow in which they reside/sleep every 4-10 days. This burrow can then become occupied by another wombat [18]. Because asynchronous burrow sharing occurs among bare-nosed wombats it is thought that bedding chambers within burrows are the likely site where mite fomites transfer to and from wombats. Laboratory data show that off-host survival of $S$. scabiei is strongly influenced by temperature and humidity conditions, with a peak survival of 19 days at $10^{\circ} \mathrm{C}$ and $97 \%$ relative humidity [1]. Thus, technological advances in the capacity to enter, navigate and record conditions within wombat burrows are valuable for understanding the ecology of this iconic marsupial and also the transmission of S. scabiei among individuals.

Given the safety, size, and environmental constraints, we have turned to robotics which have a long history in operating similarly constrained environments. Existing constrained robotic operating environments cover a wide range including infrastructure sectors (e.g. sewer pipe [7, 26], bridge [30] or HVAC inspection [3]), disaster management $[13,21]$ and powerline inspection [24]).

Aside from some aerial radio-telemetry and surveying applications $[2,8,9]$ robots haven't been heavily used in wildlife and conservation ecology besides getting closeup footage for documentaries [12]. What we see far more commonly in robotics research is biomimicry where engineers derive inspiration for their designs from clever design elements that we see in the natural world. These may vary from methods of locomotion (e.g. flapping Micro Air Vehicles) through sensing, decision making, and construction $[6,10,22,27]$.

For robotic locomotion, there are many possible solutions that may be applied (e.g. tracks, wheels, inch-worm, walking, rotors, adhesion) with specific system requirements (e.g. speed, environment, traction, stability) acting as constraints. Likewise, there are numerous possibilities in the selection of pickup tools (e.g. finger grippers, electromagnets, jamming, soft) with a selection to be made based on suitability and system requirements (e.g. material, size, compliance) [11]. 
The purpose of this study is to evaluate the efficacy of a mobile robot (WomBot as shown in Fig. 1) designed specifically for subterranean exploration of wombat burrows. This exploration provides a low impact, rapid means of burrow exploration and understanding of environmental conditions which may have significant implications on wombat health.

This paper is structured as follows: Section 2 presents the system requirements which govern the design and performance aspects of the robot design. Following this, Sect. 3 describes the design and implementation of the robot and covers all the major sub-systems. Section 4 presents and discusses the experimental results both in the laboratory and in field-testing. Finally concluding remarks are provided in Sect. 5 .

\section{System requirements analysis}

The operating environment in which WomBot operates (inside wombat burrows), puts some unique design constraints on the developed system. These can be summarised as follows:

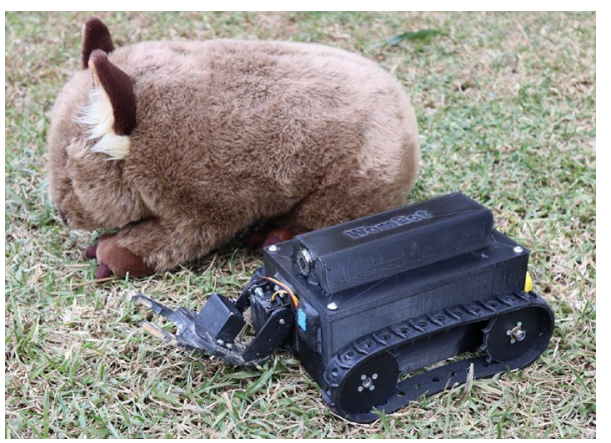

Fig. 1 Wombat robot alongside a model wombat for comparison
- Mobility: burrows are very irregular, muddy, and have steep inclines and $90^{\circ}$ turns

- Signal Propagation: burrows are underground with poor wireless signal propagation

- Awareness: vision system should allow the direction of travel and obstacles to be observed

- Size: constrained to approximately $300 \mathrm{~mm} \times 250 \mathrm{~mm} \times$ $180 \mathrm{~mm}(\mathrm{~L} \times \mathrm{W} \times \mathrm{H})$

Having considered the design constraints on the system, we now apply ISO/IEC 25010:2011 [14] to analyse the design context in terms of system quality requirements. Some of the characteristics are not relevant to the specific WomBot context and thus have been excluded. ISO/ IEC 25010:2011 consists of two elements: a quality in use model and a product quality model. Table 1 summarises the relevant elements of the quality in use model. These should be considered as the consequence and impact of any interactions between the system and relevant stakeholders. Table 2 summarises the relevant characteristics that relate to both dynamic and static system properties. Although the standard lists 8 characteristics, only 5 of these (Functional Suitability, Usability, Reliability, Security, Portability) were relevant in this context.

\section{System design and implementation}

In this section, we describe the design parameters and implementation details for the WomBot robot. Figure 2 shows a block diagram view of the robot system.

The power for the robot is supplied by three 18650 lithium-ion battery cells, giving a nominal voltage of 11.1V. These batteries drive the motors, power the microcontrollers, sensors, and ethernet module. Separate power is supplied to the cameras using the commercial camera supply and recording module.

Table 1 Analysis of quality in use

\begin{tabular}{|c|c|c|}
\hline Characteristics & Sub-characteristics & Requirement \\
\hline Effectiveness & & Traverse through and manipulate objects within burrow. \\
\hline Efficiency & & Rapid deployment and faster than excavation or drilling. \\
\hline \multirow[t]{2}{*}{ Satisfaction } & Usefulness & Allows scientists to non-destructively explore within wombat burrows. \\
\hline & Trust & $\begin{array}{l}\text { Direct visual inspection gives a better insight compared with GPR (GPR uses radar } \\
\text { pulses to observe the boundariesand depths of different buried materials). }\end{array}$ \\
\hline \multirow[t]{2}{*}{ Freedom from risk } & Health and safety risk mitigation & $\begin{array}{l}\text { Avoids dangers associated with confined space entry and hazards of encountering } \\
\text { wombats. }\end{array}$ \\
\hline & Environmental risk mitigation & Avoids modifying burrow or making it unsuitable foroccupancy. \\
\hline \multirow[t]{2}{*}{ Context coverage } & Context completeness & Serves observational and manipulation needs within wombat burrows. \\
\hline & Flexibility & $\begin{array}{l}\text { Subject to size limitations, could be used for explorationinto other burrows and } \\
\text { confined spaces (e.g. service tunnels, HVAC). }\end{array}$ \\
\hline
\end{tabular}


Table 2 Analysis of product quality

\begin{tabular}{|c|c|c|}
\hline Characteristics & Sub-Characteristics & Requirements \\
\hline \multirow[t]{2}{*}{ Functional Suitability } & Functional completeness & $\begin{array}{l}\text { System provides sufficient manoeuvrability, data collection and dexterity for manipu- } \\
\text { lation to collect objects. }\end{array}$ \\
\hline & Functional appropriateness & Facilitates exploration, observation, environmental sensing and manipulation. \\
\hline \multirow[t]{3}{*}{ Usability } & Operability & $\begin{array}{l}\text { Uses gaming remote for fast training and ease of control, vision view for direction of } \\
\text { travel. }\end{array}$ \\
\hline & Learnability & Training time $<10 \mathrm{~min}$, setup time $<5 \mathrm{~min}$ \\
\hline & User error protection & Reverse polarity protection, heartbeat stops motors if communications interrupted. \\
\hline \multirow[t]{2}{*}{ Reliability } & Fault tolerance & $\begin{array}{l}\text { Camera system decoupled from control systems, checksum on packets, heartbeat on } \\
\text { data, software v }\end{array}$ \\
\hline & Recoverability & $\begin{array}{l}\text { Communications can be re-established by unplugging and plugging cable back in, } \\
\text { rope tether for manual removal. }\end{array}$ \\
\hline Security & Integrity & Point to point wired connection, all data logged locally in a CSV file. \\
\hline \multirow[t]{2}{*}{ Portability } & Adaptability & $\begin{array}{l}\text { Adaption with minimal modification for other confined space exploration (e.g. caves, } \\
\text { HVAC). }\end{array}$ \\
\hline & Installability & Entire system weighs $<3 \mathrm{~kg}$ and can be carried by hand in two hard cases. \\
\hline
\end{tabular}

Fig. 2 WomBot system block diagram
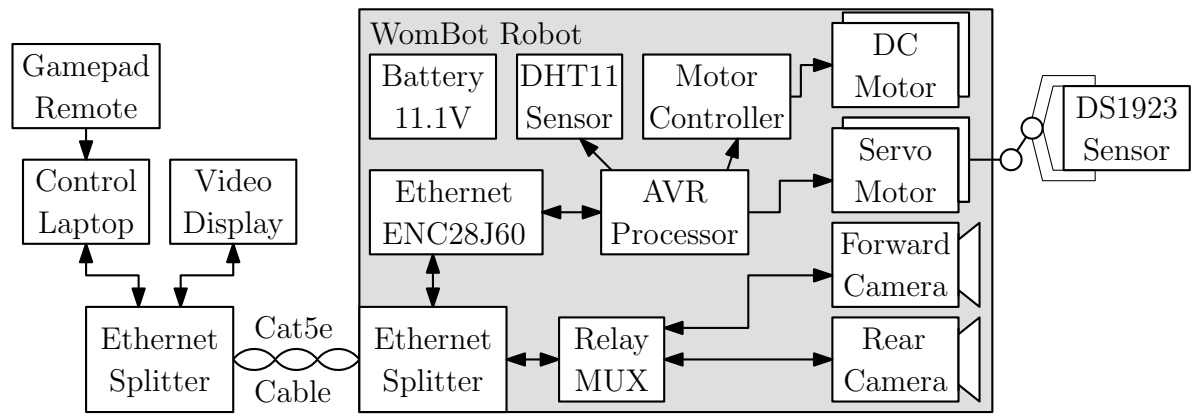

Table 3 Communications packet structure robot to PC

$\$$ WR, $<$ Battery $\rangle_{,}<$Humidity $>_{,}<$Temperature $>$

,$*<\mathrm{CS}><$ CRLF $>$

$<$ Battery $>$

$<$ Humidity $>$

$<$ Temperature $>$

$<\mathrm{CS}>$

Battery voltage (e.g. 11.1)

Relative humidity percentage

Temperature in ${ }^{\circ} \mathrm{C}$

LRC based checksum

The robot communicates back to the surface using a single 20 metre long ethernet cable. Initially, a WiFi connection was investigated with high-power directional antennas, but very high attenuation over a short distance into the burrow made this option infeasible. The robot and computer communicate using Universal Datagram Protocol (UDP) packets transmitted at $200 \mathrm{~ms}$ intervals. The datagram packets contain all control variables and data collected and are outlined in Tables 3 and 4 . A watchdog communications heartbeat was implemented where, if no packets were recorded for $500 \mathrm{~ms}$, the motors would stop to avoid damaging or getting the robot stuck.

Given the irregular operating environment, it was preferable to have both forward facing and rearward facing vision for exploring and retrieving the robot from the burrow respectively. Initially, this was prototyped using a pantilt-zoom (PTZ) network camera, but the size constraints
Table 4 Communications packet structure PC to robot

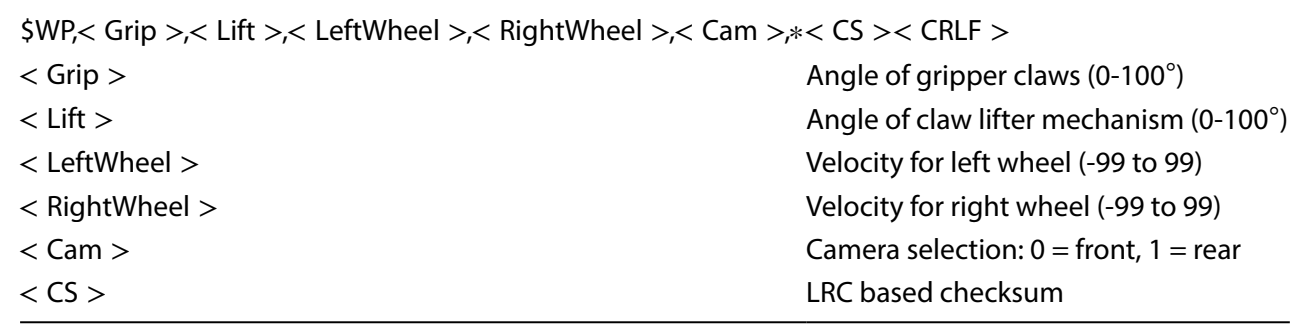


and significant scratching of the dome necessitated a more compact and robust solution. Hence, two wide-angle drain inspection cameras were installed in forwards and rearwards configuration (Fig. 3A shows the rear camera). These cameras are sealed, tough, and have built-in illumination. In contrast to the PTZ network camera-based solution, the cameras operate using 4 wires (power, ground, vision, and lighting control) which were amply accommodated with the four unused wires in the ethernet cable by way of a pair of ethernet splitters. As there are two cameras, with only one camera at a time realistically being required, a relay was used to multiplex the camera and lighting wires between the front and rear cameras to control which camera would be active. The vision from the cameras is displayed on a monitor which supports video recording onto a flash memory card (Fig. 3B).

A two degree of freedom (DoF) gripper was provided to allow manipulation of items within the burrows (e.g. environmental sensors or insect traps) based on operational requirements. The gripper is driven by two low-powered servo motors and control was achieved by one of the joysticks on the controller [25].

The microcontroller code for the robot was written in $\mathrm{C}$ and the PC controller software was written in C\#. The WomBot robot is teleoperated using a gamepad style remote as shown in Fig. 4. The left analog joystick was used the control the velocity of both sets of tracks, the right analog joystick was used to control the gripper and the select button was used to toggle the camera betweent the forward and reverse views. The gamepad controller is connected to the computer via USB.

Given the challenging operating environment (sharp turns, inclines, and mud), a tracked drive system using tank steering was implemented. An earlier experimental version (Fig. 5) was trialed but would quickly lose traction in the presence of mud and became quite susceptible

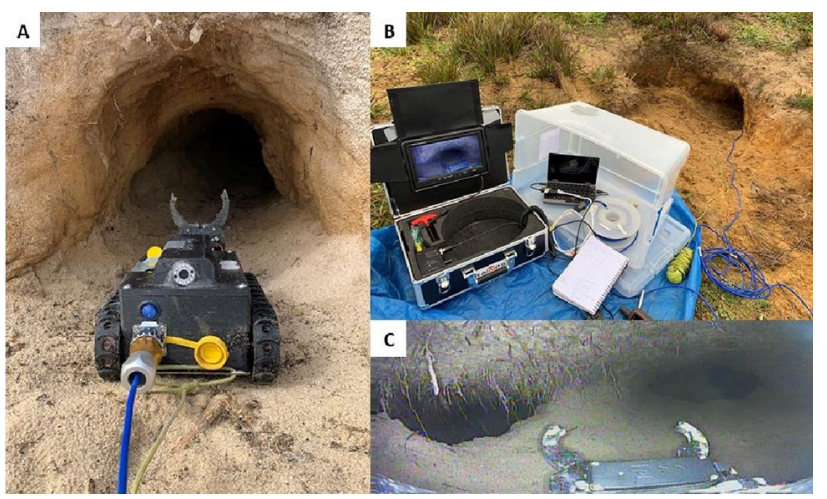

Fig. 3 a Wombat robot about to enter burrow. b Ground control station with ethernet cable running to burrow. c View from robot inside burrow

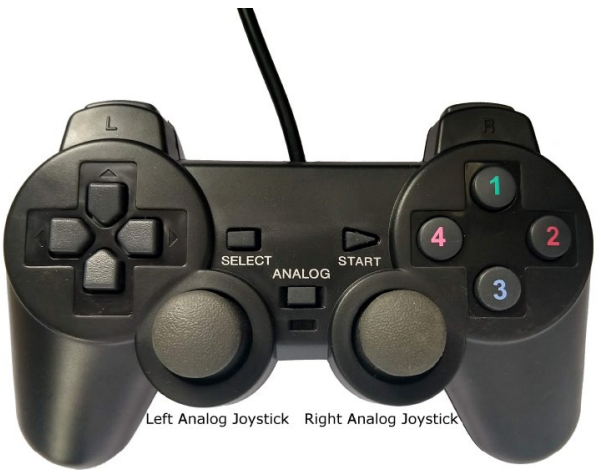

Fig. 4 Gamepad controller layout

to getting stuck. Other forms of robot locomotion were considered, including snake-locomotion, but these were avoided due to the increased complexity around using a gripper system for sensor retrieval. The robot chassis is $3 \mathrm{D}$ printed from durable co-polyester (CPE) to provide a lightweight platform that won't tend to sink into the mud. In case of robot failure or if the robot gets stuck, a rope mounting point was also provided onto the chassis to allow the robot to be extracted without excavating the wombat burrow.

An IMU (NGIMU) was affixed to the robots to provide a determination of the robot position and orientation. Given this data, we can reconstruct the (approximate) path and pose of the robot as it traverses through the wombat burrow.

The safety of any wombats that we might inadvertently encounter was considered. Wombats have a reputation for using their hard backside to plug up burrows and hence protect the more vulnerable parts of their bodies [5]. Although the size and strength characteristics of the robot

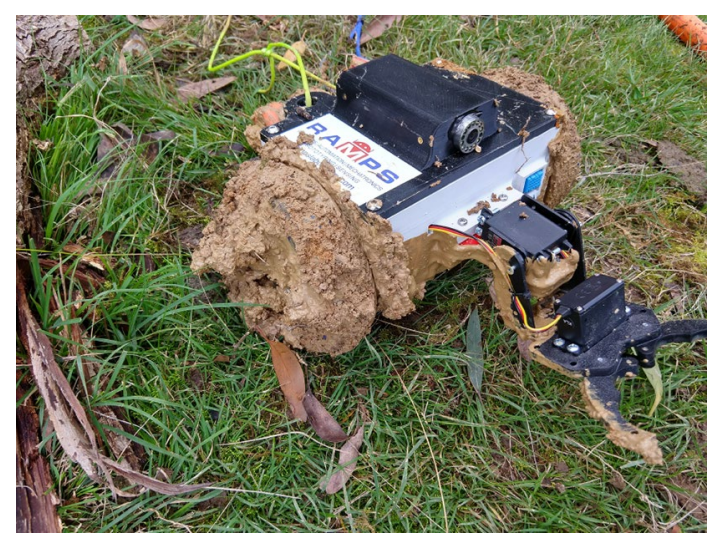

Fig. 5 An early WomBot prototype using omniwheels and two main drive wheels which were quickly encased in mud during Victorian field trials with a soil containing significant clay 
and wombat heavily favour the wombat ( $2 \mathrm{~kg}$ vs $20 \mathrm{~kg}$ ) the decision was made not to engage with any wombats discovered (and to retreat immediately) even though the risk of entanglement was minimal. A rope attached to the robot could further help in moving the robot to prevent any failure stranding the robot within the burrow. The robot tracks have been left uncovered to avoid risk of guards getting clogged with mud or sand which can more easily fall off when not enclosed.

\section{Results and discussion}

This section evaluates the performance of the robot based on laboratory and field work data (as tested within wombat burrows in Northern Tasmania). Based on the surrounding soil composition, these burrows were sandy so were less muddy.

Figures $3 C, 6 \mathrm{~A}$, and $6 \mathrm{~B}$ visually highlight different aspects and characteristics of the use of the robot within burrows. Figures $3 \mathrm{C}$ demonstrates some of the complexity of wombat burrows which may contain multiple forks and steep inclines. We can also observe burrow irregularities and the presence of tree water roots coming down from the top of the burrow.

Figure 6A shows the view from the rear camera as the robot is being retracted. This rear view is important to avoid driving the robot into obstacles, particularly going around bends and to observe the position and slack in the rope and cable tether. Finally, Fig. $6 \mathrm{~B}$ shows a wombat blocking up the burrow approximately $2 \mathrm{~m}$ ahead. The robot was quickly retracted after the wombat was observed so as not to provoke a territorial reaction from the wombat.
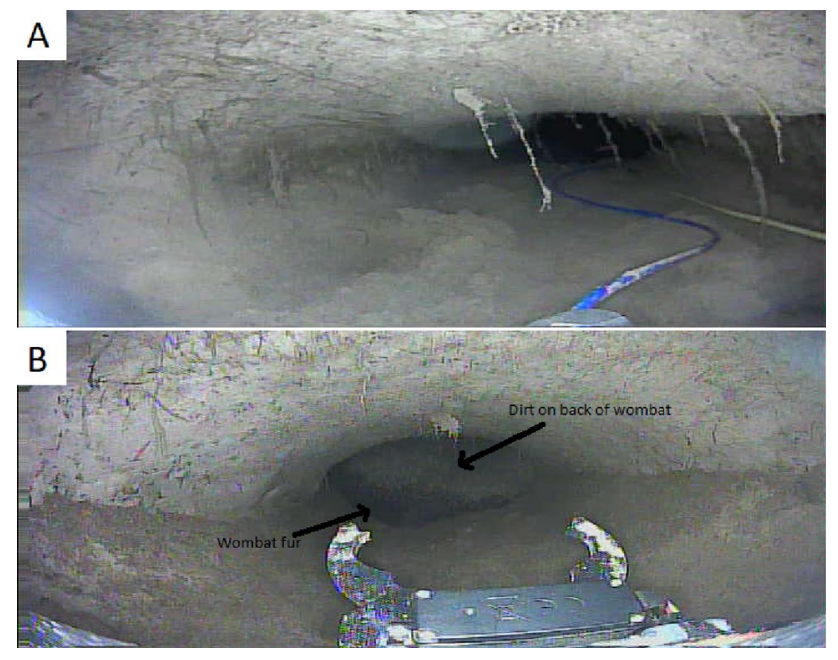

Fig. 6 a View from rear camera as WomBot is retracted from a burrow. $\mathbf{b}$ A wombat blocking the burrow ahead
The total robot weight is $2.0 \mathrm{~kg}$, making it portable enough to carry and deploy in remote areas. The gripper was tested and was able to carry a weight of up to $209 \mathrm{~g}$. This is significantly more than required as it was primarily designed for dropping off and retrieving lightweight sensor packages. We conducted laboratory experiments on the efficacy of the gripper in retrieving the sensor packages.

A Hygrochron DS1923 sensor data logger was used and three different 3D printed sensor holders were tested (pictured in Fig. 7). As the sensors may be disturbed either by wombats or when they are placed, we performed testing both with the sensors in their upright position and when knocked over on their side. Each sensor holder was tested 5 times and was performed by the same operator with minimal training. Each sensor was approached by the robot from a distance of $100 \mathrm{~mm}$ with the gripper half-way up (position most suitable for burrow traversal). Hence, the recorded time for retrieving the sensor included: approaching the sensor, lowering the gripper, grabbing the sensor and finally lifting up the gripper.

Table 5 summarises the results from the gripper experiments. Although the gripper has been used effectively on all sensor holder designs, the lattice design is a clear winner with the lowest average time and least number of missed pickups.

The robot teleoperation is velocity controlled and was speed limited to a top-speed of $0.15 \mathrm{~m} / \mathrm{s}$, which is relatively slow, but is well suited to the operating environment. Given the irregular terrain, the robot is typically be driven far slower than this as the slow speed helps in effective manoeuvring.

The maximum incline that the robot can climb was tested in a laboratory environment using a smooth laminate shelf. The robot was able to climb inclines up to $22^{\circ}$. If the robot goes down a steeper incline than this, the tether can be used to provide some tension to ensure that it can be retrieved.

The robot facilitates two forms of environmental sensing. Firstly, instantaneous sensing based on the on-board DHT11 sensor provides temperature and relative humidity data at 1 second sampling intervals. The DHT11 contains a capacitive humidity sensor and a thermistor (for measuring humidity and temperature respectively) and outputs data in a digital form. The onboard sensor was used to sample environmental conditions at the burrow entrance and within burrows. The burrows tested (during September which is springtime in Tasmania) demonstrate significant uniformity of environmental conditions underground between different burrows and at different locations along the different burrows (summarized in Table 6). In general, the relative humidity increases further down the burrow compared to the entrance of the burrow, whilst 
Fig. 7 3D Printed Sensor Holders with sensors inserted (Left-to-Right): Flat-Top, Lattice, Pole (top-upright, bottomknocked over)
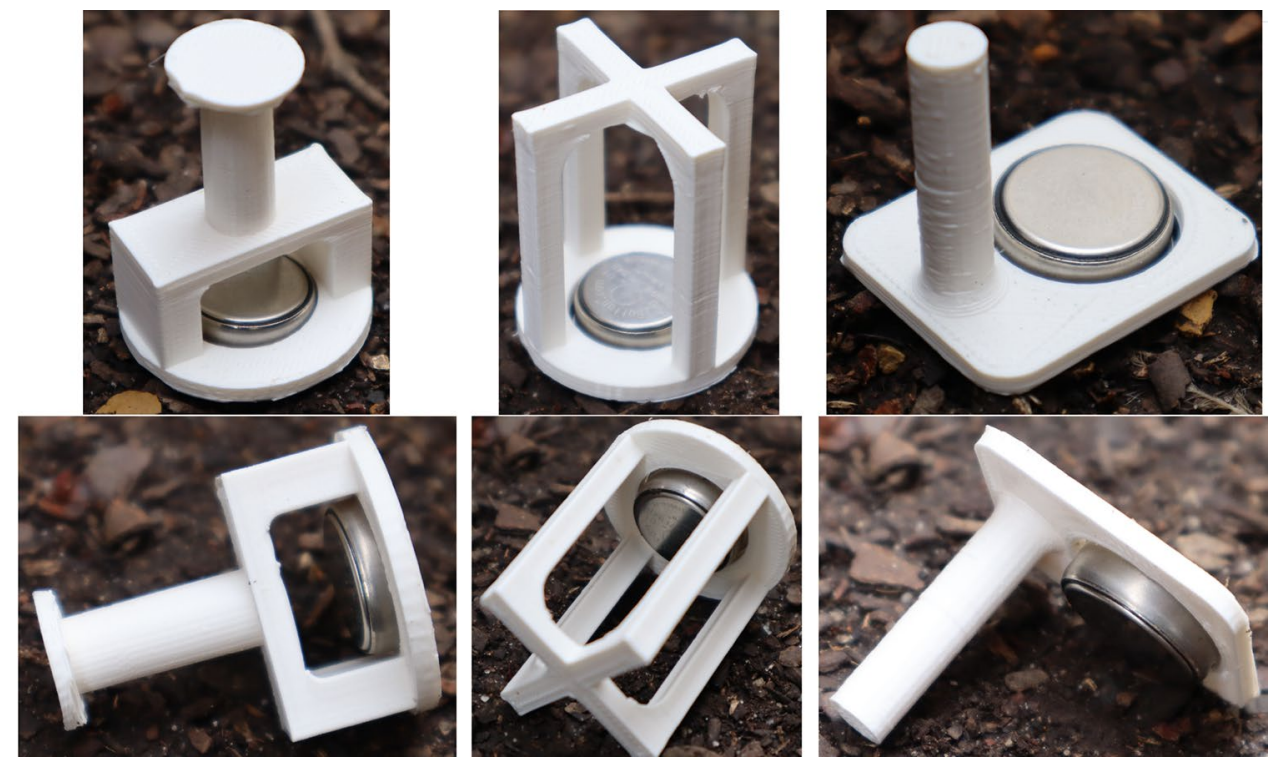

Table 5 Testing of gripper and sensor holder effectiveness

\begin{tabular}{|c|c|c|c|c|c|c|c|}
\hline \multirow[t]{2}{*}{ Attempt } & \multirow[t]{2}{*}{ Position } & \multicolumn{3}{|c|}{ Time (seconds) } & \multicolumn{3}{|c|}{ Missed pickup attempts } \\
\hline & & Flat-Top & Lattice & Pole & Flat-Top & Lattice & Pole \\
\hline 1 & Upright & 28 & 14 & 30 & 2 & 0 & 1 \\
\hline 2 & Upright & 18 & 18 & 28 & 0 & 0 & 1 \\
\hline 3 & Upright & 23 & 13 & 38 & 1 & 0 & 3 \\
\hline 4 & Upright & 28 & 18 & 34 & 1 & 1 & 1 \\
\hline 5 & Upright & 25 & 20 & 35 & 0 & 0 & 2 \\
\hline 1 & Knocked & 14 & 22 & 20 & 0 & 0 & 0 \\
\hline 2 & Knocked & 19 & 16 & 17 & 0 & 0 & 0 \\
\hline 3 & Knocked & 14 & 14 & 17 & 0 & 0 & 0 \\
\hline 4 & Knocked & 19 & 18 & 14 & 0 & 0 & 0 \\
\hline 5 & Knocked & 25 & 21 & 14 & 1 & 1 & 0 \\
\hline Average & & 21.3 & 17.4 & 24.7 & 0.5 & 0.2 & 0.8 \\
\hline Standard deviation & & 5.3 & 3.1 & 9.3 & 0.7 & 0.4 & 1.0 \\
\hline
\end{tabular}

the temperature remains uniform throughout. Interestingly, the temperature increased (not shown on graph) to approximately $18^{\circ} \mathrm{C}$ when a wombat was present (measured from approximately 2 meters), as a result of the wombat body heat.

In Tasmania, the month of October has higher than average $(66.5 \mathrm{~mm})$ rainfall when compared to the annual rainfall ( $56.1 \mathrm{~mm}$ in Launceston). Winter months (e.g. August) have significantly higher average rainfall $(85.9 \mathrm{~mm}$ for the month) and summer months have much lower rainfall $(31.3 \mathrm{~mm}$ for February). The tracked system tends to handle wetter conditions better than the wheels as it has a significantly larger contact surface area, it better distributes the weight and as the shape of the tracks change as they go around the elliptical path some dirt is removed.

The second form of environmental testing facilitated by the robot (using the Hygrochron DS1923 integrated
Table 6 Environmental sensing data

\begin{tabular}{llll}
\hline $\begin{array}{l}\text { Burrow num- } \\
\text { ber }\end{array}$ & Location & $\begin{array}{l}\text { Temperature } \\
{ }^{\circ} \mathrm{C}\end{array}$ & $\begin{array}{l}\text { Relative } \\
\text { humid- } \\
\text { ity }\end{array}$ \\
\hline 1 & Entrance & 18 & 70 \\
1 & $4.5 \mathrm{~m}$ inside & 15 & 82 \\
2 & Entrance & 15 & 81 \\
2 & Bedding chamber & 14 & 91 \\
3 & Entrance & 15 & 87 \\
3 & $4.5 \mathrm{~m}$ inside & 15 & 91 \\
4 & Entrance & 15 & 87 \\
4 & $4.5 \mathrm{~m}$ inside & 15 & 88 \\
4 & $4.5 \mathrm{~m}$ inside & 15 & 90 \\
\hline
\end{tabular}


logging sensor deployed and retrieved by the robot) allows for logging of environmental conditions (e.g. every 10 minutes for 24 hours). Figure 8, contains temperature data measured using this sensor for three different burrows over 24 hours. This data highlights that the temperature within different burrows remain mostly constant over the day. These measurements were taken at the burrow end-point which in this case was 6, 7.5, and $7.7 \mathrm{~m}$ for the different burrows selected. The relative humidity data (Fig. 9) also remains high, although tends to decrease slightly overnight.

In contrast to the stable environmental conditions recorded within the burrow, conditions recorded outside the burrow were significantly more variable and cyclic (not shown) in line with normal outdoor weather conditions. Typical temperatures varied from 3 to $15^{\circ} \mathrm{C}$ and relative humidity varied from 70 up to $95 \%$.

Arlian et al. experimentally characterized survival and infestivity of scabies mites for different environmental conditions [1]. In general, the female mites would survive approximately twice as long as the male mites and mite survival time was highest at a temperature of $10^{\circ} \mathrm{C}$ and high relative humidity ( $75 \%$ and $97 \%$ ). Unfortunately for wombat conservation, these peak mite survival conditions are similar to those found within wombat burrows.
Fig. 8 Air temperature data collected from within three burrows (September 2020, Cape Portland, Tasmania)
Fig. 9 Relative humidity data collected from within three burrows (September 2020, Cape Portland, Tasmania)
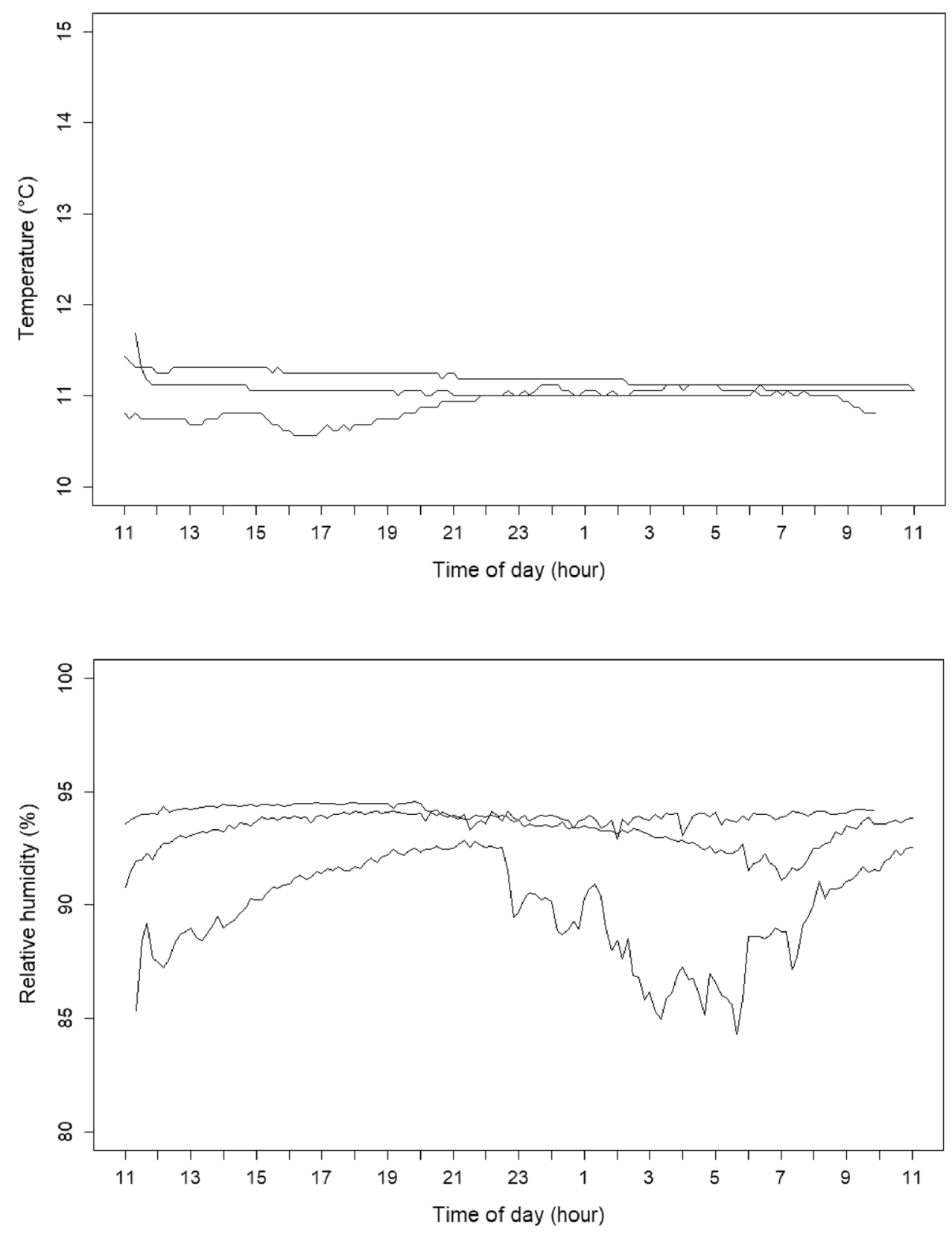
Based on Arlian's characterizations we can estimate female mite survival time of 16-18 days within the burrow, and 9-10 days at the burrow entrance (where seasonally for at least for part of the day, the temperature may be higher and the relative humidity may be lower).

Arlian et al. also observed $100 \%$ mite mortality at a temperature of $50^{\circ} \mathrm{C}$ for 10 minutes. Hence one possible use of the robot could involve mapping out a burrow to ensure it is empty and that all entrances are blocked off so that the burrow can be temporarily heated to irradicate mites. Alternatively, with minimal modifications, the robot could be used as an insecticide delivery platform. It is not known if such treatments would deter wombats from visiting burrows, would adversely affect burrow or where precisely any insecticide should be dispensed. Likewise, we have not yet studied if any scent left by the robot deters wombats from re-entering burrows.

\section{Conclusions}

Given the widespread disease and mortality that mange has brought to wombats, it is important to understand the conditions where the mites that cause this mange is most prevalent. Since wombats are nocturnal and live in burrows which they share, the conditions within these burrows may unlock important information on the spread and severity of mange on a wombat population. These burrows tend to be relatively small, moist, have sharp turns, and steep inclines - all of which make studying them a difficult prospect.

In this paper, we describe and evaluate a compact teleoperated robot designed for performing research within wombat burrows. We now consider the extent to which our requirements were met and discuss possible future directions. In terms of meeting our requirements, we refer back to our requirements columns in the two tables Quality in Use (Table 1) and Product Quality (Table 2).

In terms of quality of use, we developed a teleoperated robot which, allows reliable sensor placement and retrieval, is compact, teleoperated, and highly manoeuvrable to allow researchers to traverse the difficult terrain within wombat burrows. The robotic solution gives a clear view of what is happening inside burrows and significantly reduces safety and environmental risk as it is non-destructive and negates the need for entry into confined spaces. Consequently, we claim that our overall objective was largely achieved, that is, we have a robotic system that can be used to explore and study wombat burrows.

In terms of product quality, the field testing has validated that the WomBot robot is capable of traversing wombat burrows and had sufficient manipulator dexterity to place and retrieve objects. This allowed for sensors and test platforms to be deployed and retrieved to study the burrow conditions and prevalence of mange-causing mites. Given the simple operability, and lightweight design, coupled with the built-in fault-tolerance, we expect such a robotic platform may have broad applicability in other confined space locations (e.g. HVAC, inspection under houses). We envisage future work in this area could include further robotic enhancements (e.g. insecticide dispensing within sleeping chambers), point-cloud burrow reconstruction and collection of soil samples to study mite prevalence.

Acknowledgements We thank MrTim Stokes from UPCC for his assistance in gaining access to wombat burrows for preliminary field trials during the development phase. We thank the journal reviewers for their detailed feedback which has further enhanced manuscript.

Author Contributions R. Ross: System Design and Development, Testing, Paper Authorship. S. Carver: System Design, Field Testing, Data Analysis, Paper Writing. E. Browne: Field Testing, Data Analysis. B.S. Thai: System Design and Development.

\section{Declarations}

Conflict of interest The authors declare no conflict of interest.

Availability of data and material No additional data is available.

Code availability Available on request.

Open Access This article is licensed under a Creative Commons Attribution 4.0 International License, which permits use, sharing, adaptation, distribution and reproduction in any medium or format, as long as you give appropriate credit to the original author(s) and the source, provide a link to the Creative Commons licence, and indicate if changes were made. The images or other third party material in this article are included in the article's Creative Commons licence, unless indicated otherwise in a credit line to the material. If material is not included in the article's Creative Commons licence and your intended use is not permitted by statutory regulation or exceeds the permitted use, you will need to obtain permission directly from the copyright holder. To view a copy of this licence, visit http://creativecommons. org/licenses/by/4.0/.

\section{References}

1. Arlian L, Runyan R, Achar S, Estes S (1984) Survival and infestivity of sarcoptes scabiei var. canis and var. hominis. J Am Acad Dermatol 11(2):210-215

2. Bayram H, Stefas N, Isler V (2018) Aerial radio-based telemetry for tracking wildlife. In: 2018 IEEE/RSJ international conference on intelligent robots and systems (IROS), IEEE, pp 4723-4728

3. Beckett $A$, Ross $R$ (2017) Pyroshield-a hvac fire curtain testing robot. Auto Construct 81:234-239

4. Bornstein S, Mörner T, Samuel WM (2001) Sarcoptes scabiei and sarcoptic mange. Para Dis Wild Mammals 2:107-19

5. Boseley M (2020) Wombats' deadly bums: how they use their "skull-crushing" rumps to fight, play and flirt. Anim Behav 5:137 
6. Cao C, Burgess S, Conn AT (2019) Toward a dielectric elastomer resonator driven flapping wing micro air vehicle. Front Robo Al 5:137

7. Chataigner F, Cavestany P, Soler M, Rizzo C, Gonzalez JP, Bosch C, Gibert J, Torrente A, Gomez R, Serrano D (2020) Arsi: an aerial robot for sewer inspection. In: Advances in Robotics Research: From Lab to Market. Springer, pp 249-274

8. Cliff OM, Fitch R, Sukkarieh S, Saunders DL, Heinsohn R (2015) Online localization of radio-tagged wildlife with an autonomous aerial robot system. Robot Sci Syst

9. Cliff OM, Saunders DL, Fitch R (2018) Robotic ecology: tracking small dynamic animals with an autonomous aerial vehicle. Sci Robot 3(23)

10. Coyle S, Majidi C, LeDuc P, Hsia KJ (2018) Bio-inspired soft robotics: material selection, actuation, and design. Extreme Mech Lett 22:51-59

11. D'Avella S, Tripicchio P, Avizzano CA (2020) A study on picking objects in cluttered environments: exploiting depth features for a custom low-cost universal jamming gripper. Robot Comput Integ Manuf 63:101888

12. Grigonis HK (2017) Spy in the wild: BBC documentary hides cameras inside robotic animals. [Online]. Available: https://www. digitaltrends.com/photography/robotic-animals-hidden-camer as/

13. Hu J, Liang Y, Diao X (2017) A flying-insect-inspired hybrid robot for disaster exploration. In: 2017 IEEE international conference on robotics and biomimetics (ROBIO), IEEE, pp 270-275

14. ISO/IEC (2011) 25010:2011, Systems and software engineering - systems and software quality requirements and evaluation (SQuaRE) — system and software quality models

15. Martin AM, Skerratt LF, Carver S (2017) Sarcoptic mange in Australian wildlife. [Online]. Available: https://www.wildlifehealtha ustralia.com.au/Portals/0/Documents/FactSheets/Mammals/ SarcopticMangeinAustralianWildlife.pdf

16. Martin AM, Burridge CP, Ingram J, Fraser TA, Carver S (2018a) Invasive pathogen drives host population collapse: effects of a travelling wave of sarcoptic mange on bare-nosed wombats. J Appl Ecol 55(1):331-341

17. Martin AM, Fraser TA, Lesku JA, Simpson K, Roberts GL, Garvey J, Polkinghorne A, Burridge CP, Carver S (2018b) The cascading pathogenic consequences of sarcoptes scabiei infection that manifest in host disease. Royal Society open science 5(4):180018

18. Martin AM, Richards SA, Fraser TA, Polkinghorne A, Burridge CP, Carver S (2019) Population-scale treatment informs solutions for control of environmentally transmitted wildlife disease. J Appl Ecol 56(10):2363-2375

19. Mcllroy JC (1973) Aspects of the ecology of the common wombat vombatus ursinus (shaw, 1800). In: Ph D thesis, Australian National University
20. Mounsey KE, Bernigaud C, Chosidow O, McCarthy JS (2016) Prospects for moxidectin as a new oral treatment for human scabies. PLoS Negl Trop Dis 10(3):e0004389

21. Niroui F, Zhang K, Kashino Z, Nejat G (2019) Deep reinforcement learning robot for search and rescue applications: Exploration in unknown cluttered environments. IEEE Robot Autom Lett 4(2):610-617

22. Oh H, Shirazi AR, Sun C, Jin Y (2017) Bio-inspired self-organising multi-robot pattern formation: a review. Robot Auton Syst 91:83-100

23. Pence D, Ueckermann E (2002) Sarcoptic mange in wildlife. Revue Scientifique et technique-Office international des Epizooties 21(1):385-398

24. Richard PL, Pouliot N, Morin F, Lepage M, Hamelin P, Lagac M, Sartor A, Lambert G, Montambault S (2019) Lineranger: Analysis and field testing of an innovative robot for efficient assessment of bundled high-voltage powerlines. In: 2019 International conference on robotics and automation (ICRA), IEEE, pp 9130-9136

25. Ross $R$ (2014) Investigation into soft-start techniques for driving servos. Mechatronics 24(2):79-86

26. Ross R, Baji A, Barnett D (2019) Inner profile measurement for pipes using penetration testing. Sensors 19(2):237

27. Shi Q, Gao Z, Jia G, Li C, Huang Q, Ishii H, Takanishi A, Fukuda T (2020) Implementing rat-like motion for a small-sized biomimetic robot based on extraction of key movement joints. IEEE Trans Robot

28. Shimmin GA, Skinner J, Baudinette RV (2002) The warren architecture and environment of the southern hairy-nosed wombat (lasiorhinus latifrons). J Zool 258(4):469-477

29. Skerratt LF (2005) Sarcoptes scabiei: an important exotic pathogen of wombats. Microbiol Aust 26(2):79-81

30. Sutter B, Lelevé A, Pham MT, Gouin O, Jupille N, Kuhn M, Lulé $P$, Michaud P, Rémy P (2018) A semi-autonomous mobile robot for bridge inspection. Autom Const 91:111-119

31. Swinbourne M, Taggert D, Ostendorf B (2016) Non-invasive exploration of underground wombat tunnels. Int Soc Opt Photon Newsroom

32. Triggs B (2009) Wombats. CSIRO PUBLISHING

Publisher's Note Springer Nature remains neutral with regard to jurisdictional claims in published maps and institutional affiliations. 